\title{
The Development of Silicon Nanocomposite Materials for Li-Ion Secondary Batteries
}

\author{
Jian Wang ${ }^{*}, 1,2$, Yuan Chen ${ }^{2}$ and Lu Qi ${ }^{1}$ \\ ${ }^{1}$ College of Chemistry and Molecular Engineering, Peking University, No. 3, North Road 2 of Zhongguancun, Beijing, \\ 100190, China \\ ${ }^{2}$ CITIC Guoan Mengguli New Energy Technology Co., Ltd., No.47, Yong'an Road, Science and Technology Park, \\ Changping, Beijing, 102200, China
}

\begin{abstract}
With the rapid progress and wide application of Li-ion batteries, commercial graphite anode can not satisfy the increasing demand for higher capacities. Like other anode materials with higher capacities, silicon materials as anodes remain serious problems for their large volume variations and poor cyclabilities during cycling. One of key problem is how to stabilize the performances of $\mathrm{Si}$ anode materials. Various influencing factors of volume variation of silicon anode materials have been reviewed, which consist of discharging voltage, amorphous or crystalline type, tube or pore microstructure, interlayer adhesion, buffering and protective layer materials and conductive agents. Another hot issue is on the preparation methods for silicon anode materials with high performance. It covers not only the technics of high purity silicon materials, including the predominant Siemens process of electronic-grade silicon, but also the techniques of silicon film anodes, which consists of butyl-capped silicon precursor, the template methods of nanostructure, magnetron sputtering, ball-milling. From the screening of existing silicon anode materials in the literatures, the preparation methods for promising $\mathrm{Si}$ anode materials and their prospects have been offered.
\end{abstract}

Keywords: Li-ion secondary batteries, silicon nanocomposite materials, anode, large volume variations, electrochemical performances.

\section{INCREASING DEMANDS FOR HIGHER CAPA- CITY ANODE CANDIDATES OF LITHIUM-ION SEC- ONDARY BATTERIES}

\subsection{The Widespread Availability of Lithium-Ion Secondary Batteries}

In the early applied accumulator field, there have been various batteries, such as lead-acid batteries, nickel cadmium batteries, nickel metal hydride battery. Since 1980s, the lithium secondary batteries using $\mathrm{Li}$ metal as the anode material have been into market.

However, due to the Li dendrite formation on the anode surface, lithium metal anode are found unsafe. Therefore, Carbon materials as anodes are used widely to commercial batteries, instead of Li metal [1].

The anode materials and cathodes of $\mathrm{Li}$-ion batteries allow lithium insertion or deinsertion between the anodes and the counterpart cathodes. As shown in Fig. (1), when charged, electrons flow from the cathode to the anode, meanwhile positive $\mathrm{Li}$ ions from the anode to cathode; and contrariwise during discharged.

Carbon-intercalation materials [2] possess high mechanical stability and better capacity retention. They can form $\mathrm{Li}_{\mathrm{x}} \mathrm{C}_{6}$, such as petroleum coke carbon and graphite; the

*Address correspondence to this author at the College of Chemistry and Molecular Engineering, Peking University, No. 3, North Road 2 of Zhongguancun, Beijing, 100190, China; Tel: +86 01062753868;

Fax:+86 01062755290; E-mail: chinajwang@163.com latter can deliver a theoretical capacity $372 \mathrm{mAh} / \mathrm{g}$ due to inserting double of the lithium. Therefore, the majorities of commercial carbon anode materials are graphite or modified graphite materials at present.

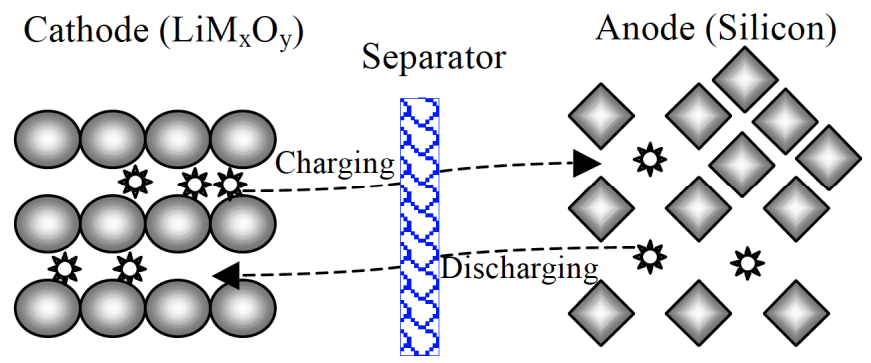

Fig. (1). Schematic of Li-ion secondary battery containing Silicon (anode) and lithium metal oxide (cathode) during charging or discharging processes.

As new scientific and technological products, the Li-ion secondary batteries have superior performance, such as high capacity, high discharge rate, stable discharge platform, nonmemory effect, so they can accomplish the scheduled tasks successfully. First of all, the Li-ion batteries have been widely applied to various portable fields, such as mobile phones, MP3 (which stands for Motion Picture Experts Group-Layer3), personal computers, etc. Moreover, vehicle batteries have been exploited, such as the 50 electric automobile of MGL (Mengguli New Energy Technology Co., Ltd.) exhibition in the Beijing Olympics of 2008. Besides, in energy storage areas, they can assist or replace the electric network to absorb more uncertainty and nonstable electrical energy, so as to make use of wind power and 
photovoltaic energy, and make the electrical energy stored regularly. In addition, using the Li-ion secondary batteries systems as the standby power of trains might be a good choice, because they are more powerful and lighter than the lead-acid batteries.

\subsection{Requirements for the Anode Candidates with Higher Capacities}

Despite of many merits of carbon anode materials and lithium titanate, low capacity is a problem too severely to fit for the ever-increasing energy demands of modern devices in more and more areas, especially the vehicle batteries. Seeking new materials for smaller, lighter, and longer-lasting batteries is a hot focus of the battery research.

Some intermetallics metals [3-11], such as $\mathrm{Sn}, \mathrm{Si}, \mathrm{Al}, \mathrm{Bi}$, $\mathrm{Pb}$, In, whose lithium-base alloys can deliver a high capacity anodic materials, especially $\mathrm{Si}$ and $\mathrm{Sn}$ can be inserted by maximum $\mathrm{Li}$ due to formation of Li-rich alloys, i.e., $\mathrm{Li}_{4.4} \mathrm{Si}$ and $\mathrm{Li}_{4.4} \mathrm{Sn}$, which can have high volume specific capacity (theoretical value $7254 \mathrm{mAh} / \mathrm{cm}^{3}$, i.e., $990 \mathrm{mAh} / \mathrm{g}$ ) and high weigh volume specific capacity (theoretical value 4200 $\mathrm{mAh} / \mathrm{g}$ ), respectively. Therefore, Si has been regarded as the subsequently promising anode materials $[12,13]$.

However, the present intermetallic materials mentioned above can not be used as commercial anode currently due to the unsafety issues and instability performance. The related major influencing factor is the large volume expansions or contraction upon lithiation or delithiation. Their volume expansion can be over $300 \%$, while graphite is merely 6$10 \%$ and possesses higher mechanical stability. Moreover, the present intermetallic materials are liable to fracture [14, 15], which results in electrical contact with the remainder of the electrode, and increases the possibility of chemical attack by corrosive agents around the surface fracture areas. There are still questions to be overcome before silicon anode materials can be used commercially.

\section{STABILIZING FACTORS OF SILICON COMPOSITE MATERIALS DURING CYCLING}

Presently, silicon composite materials as anode may bring various problems during discharging or charging processes, such as volume variation, a very large first-cycle irreversible capacity, irreversible capacities, and capacity fading.

It is necessary to study the effect factors on silicon composite materials, including structure and composition, especially the huge volume variation. So, scientists and engineers can work out solutions to build-up a commercial silicon composite material system very soon.

\subsection{Proper Charging/Discharging Programs Can Cause Minor Destruction}

According to the model analog of theoretical research [14], there are greatly different between horizontal and vertical dimensions when silicon anode is deeply discharged. The dimensions variations in horizontal directions often increase by about 2 times. While the average increment rates in vertical directions increase rapidly with the further deepdischarging. There are no significant variations in the vertical at $0.5 \mathrm{~V}$, and suddenly increases by 3 times at $0.3 \mathrm{~V}$ of discharging; furthermore, raises to 7 times at $0.2 \mathrm{~V}$; in the end, it reaches 12.6 times at about $0.1 \mathrm{~V}$.

Due to the large volume variations of silicon anode materials, especially their larger variations in the vertical dimension, the film may be brittle to fall off partially and results in bad conductivity and loss of specific capacity.

Therefore, the suitable programmed charging/discharging processes for controlling the volume variations are necessary.

\subsection{Amorphous Silicon Thin Films may have Homogeneous Volume Variations}

Monocrystalline silicon and polycrystalline silicon can not present good electrochemical properties when used in Liion secondary batteries, even though they are the main materials of the semiconductor industry and photovoltaic fields.

In crystalline materials, new intermetallic phases are formed on lithium insertion. It's the transformation between crystalline type and amorphous type. This leads to inhomogeneous volume expansions in the two-phase regions, which can cause cracking and pulverization of the material. As a result, some of the particles may lose electrical contact with the electrode, and capacity is lost.

As for amorphous silicon materials, they may show a relatively uniform of volume variations. Therefore, amorphous silicon materials receive less destructive, due to their anisotropy characteristics [34].

It seems that amorphous silicon and amorphous siliconcontaining alloys can exhibit much improved cycling performance. In amorphous alloys, including amorphous alloys of $\mathrm{Si}$ and $\mathrm{Sn}$, the expansion on lithium insertion is homogeneous. And their submicron-thickness films expand and contract reversibly without further pulverization.

Besides the crystal forms, the film thickness also has a strong effect on the electrochemical performance. Some research [35] shows that film thickness also has an effect on structural variations that occur during the lithiation of a-Si films. Only in more than 3 microns thickness of silicon film, can crystal phase form $\mathrm{Li}_{15} \mathrm{Si}_{4}$ be definitely generated during cycling at the deep discharge voltage of $30 \mathrm{mV}$.

As the silicon film thickness increases greatly, the vertical size variations might cause unexpected issues including fractures, pulverization or peeling. Thus, low conductivities and bad electrochemical performances may occur.

\subsection{Porous Structures Can Buffer the Volume Variations}

Porous structures including macroporosity, mesoporosity, microporosity, are listed in Table 1 [15, 16, 24, 38-47]. Microporous structures which size are below 2 nanometers, play an role of helping lithium-ion intercalation or deintercalation, while macroporous structures which size are above 50 nanometers, help the electrolyte storage as reservoir. Mesoporous structures which size are between 2 and 50 nanometers, also play a role of both of micropous and macroporous structures. In addition, porous materials can provide a large rate of volume for buffering the huge volume 
Table 1. Nanostructures of Si Composite Anode Materials and their Capacities

\begin{tabular}{|c|c|c|}
\hline Structures Strategies & Structures and Component Characteristic & Capacity \\
\hline mesoporous & $\begin{array}{c}\text { Mesoporous Si@Carbon Core-Shell Nanowires [39] } \\
\text { encapsulated } \mathrm{Si} \text { with mesoporous } \mathrm{TiO}_{2} \text { layer [38] } \\
\text { Mesoporous } \mathrm{Si}^{-\mathrm{TiO}_{2}}[40]\end{array}$ & $\begin{array}{c}3163 \sim 80 \text { cycles } \\
2000 \rightarrow 900 \sim 5 \text { cycles } \\
1400 \sim 50 \text { cycles }\end{array}$ \\
\hline macroporous & Three-dimensionally ordered macroporous Ni-Sn [41] & $455 \sim 30$ cycles \\
\hline nanoporous & nanoporous nanofibrous $\mathrm{Si}[42]$ & $746 \sim 30$ cycles \\
\hline Nanowires & $\begin{array}{c}\text { Crystalline-Amorphous Core-Shell Silicon Nanowires [43] } \\
\text { Mesoporous Si@Carbon Core-Shell Nanowires [39] } \\
\text { Silicon nanowire (HF-AgNO } 3 \text { etching) [24] } \\
\text { Carbon-Silicon Core-Shell Nanowires [44] } \\
\text { silicon nanowires [15] }\end{array}$ & $\begin{array}{c}1000 \sim 100 \text { cycles } \\
3163 \sim 80 \text { cycles } \\
1000 \sim 30 \text { cycles } \\
2000 \sim \\
3500 \sim 20(\mathrm{C} / 5)\end{array}$ \\
\hline nanofiber & $\begin{array}{l}\text { Carbon-fiber-silicon-nanocomposites [45] } \\
\text { carbon-silicon composite nanofiber [46] }\end{array}$ & $\begin{array}{c}700 \sim \\
1240 \sim 20 \text { cycles }(0.1 \mathrm{C})\end{array}$ \\
\hline nanotube & $\begin{array}{l}\text { Nanoscale } \mathrm{Si} \text { coating on pore-walls of } \mathrm{SnO}_{2} \text { nanotube [16] } \\
\text { Si DC MWCNTs nanocomposite [47] }\end{array}$ & $\begin{array}{l}1800-1600 \sim 90 \text { cycles } \\
733 \sim 20 \text { cycles }\end{array}$ \\
\hline
\end{tabular}

variation of silicon materials, so as to give a good electrochemical performance.

Nanostructure materials can promisingly minimize the expansion of lithiation and stabilize the electrochemical properties, while inappropriate nanostructures resulted in worse electrochemical properties [36-38]. Furthermore, compared with silicon nanowires, silicon nanotubes possess large surface area, large buffer capacity and better stability.

To buffer the silicon materials, other buffering materials are brought around the silicon sites. These materials have less or no expansions and contractions, e.g., carbon materials, titanium dioxide, copper materials, etc. And, they can be in various structures, such as fibers, nanowires, nanobelts, nanotubes, porous structures, etc. [16, 38-47].

\subsection{High Interlayer Adhesions May Prevent the Si Active Substance from Peeling}

Substrate pretreatments, including etching, corona treatment of the substrate, roughness, etc., are effective methods for increasing the attachment of silicon to substrate, enhancing the adhesion and improving conductivity properties, especially under the huge volume variation caused by the discharging or charging of silicon materials [48].

Magnetron sputtering is a preparation method as well as a pretreatment method, which enhances the adhesion between substrate and film of material through the plasma sputtering, and improves the adhesion between the particles of the film through the plasma deposition. So it possesses excellent adhesive films, compared with other deposition methods including CVD (chemical vapor deposition), evaporation techniques.

\subsection{The Stable Protective Layer Can Avoid Further Useless Corrosion}

Solid electrolyte interface (SEI) layer is usually formed when electrolyte decomposes on the anode surface during the first electrochemical cycles. The electrolyte does not further decompose on graphite surface, so graphite materials have better capacity retention [49].

The SEI of silicon-containing material is different from that of graphite. The silicon sites begin fracture during cycling, caused by the large expansions and contractions, upon Li insertion and deinsertion. The SEI layer forms and disintegrates continuously, so more and more new SEI layers form on aged layers. In the end, a thick layer inhibits $\mathrm{Li}$ diffusion in the active materials, and especially reduces the battery capacity greatly [34, 48].

In order to keep it stable, some electrolyte should be used. Vinylene carbonate can be used in minimizing the SEI thickness of metal-based anodes, which can form a stable thickness SEI layer [50]. In addition, some outer surfaces are formed with the mixture of various oxide and/or carbon, so as to protect the silicon materials.

\subsection{The Conductive Agents Doped May Improve the Electrical Properties}

Due to a low conductivity of silicon materials, it is unfit for discharging at high rate instantaneously. To improve the conductivity, some conductive agents are often used, including acetylene black, carbon black, polyaniline, carbon nanotubes [18, 47, 55, 73]. Moreover, aluminum and tin are good candidates, which provide good electrical conductivity as well as high specific capacity, for their being active anode materials.

\section{VARIOUS PREPARATION METHODS FOR THE SI COMPOSITE ANODE MATERIALS}

\subsection{Preparation Techniques for Silicon Materials}

Silicon element in the earth shell is abundant, widely available, and inexpensive. However, the pure silicon materials are expensive for their high cost and complex process.

There have been some key methods for preparation of silicon with different purity. Metallurgical-grade silicon, whose purity is about $98.5 \%$, is usually prepared by reducing 
silica sand or quart with coke for metallurgy (shown in Reaction 1). Electronic-grade silicon as one of important semiconductor materials, whose purity is above $99.9999999 \%(9 N)$, is achieved by the modified Siemens Method, which is of high cost and low productivity (shown in Reaction 2) containing a series of process: hydrochlorination of metallurgical-grade silicon, fractional distillation of trichlorosilane, hydrogen reduction. Solar grade silicon as the major solar cell materials whose purity is around $99.9999 \%(6 \mathrm{~N})$, is produced by silane decomposition method by Union Carbide Corporation (shown in Reaction 3) and National Laboratorys in USA (shown in Reaction 4) or other method hydrochloric treatment of silicate method by Kawasaki Steel and Flat glass company in Japan, etc. These reactions are shown below:

$\mathrm{SiO}_{2}+\mathrm{C} \rightarrow \mathrm{Si}+\mathrm{CO}_{2}$

$3 \mathrm{HCl}+\mathrm{Si} \rightarrow \mathrm{SiHCl}_{3}+\mathrm{H}_{2} ; \mathrm{SiHCl}_{3}+\mathrm{H}_{2} \rightarrow 3 \mathrm{HCl}+\mathrm{Si}$

$3 \mathrm{SiCl}_{4}+\mathrm{Si}+2 \mathrm{H}_{2} \rightarrow 4 \mathrm{SiHCl}_{3} \fallingdotseq 2 \mathrm{SiH}_{2} \mathrm{Cl}_{2}+2 \mathrm{SiCl}_{4}$

$3 \mathrm{SiH}_{2} \mathrm{Cl}_{2} \fallingdotseq 2 \mathrm{SiHCl}_{3}+\mathrm{SiH}_{4} ; \mathrm{SiH}_{4} \rightarrow \mathrm{Si}+2 \mathrm{H}_{2}$

$3 \mathrm{C}_{2} \mathrm{H}_{5} \mathrm{OH}+\mathrm{Si} \rightarrow \mathrm{H}_{2}+\mathrm{Si}\left(\mathrm{OC}_{2} \mathrm{H}_{5}\right)_{3}, \mathrm{Si}\left(\mathrm{OC}_{2} \mathrm{H}_{5}\right)_{3}$

$\rightarrow 0.25 \mathrm{SiH}_{4}+3 \mathrm{Si}\left(\mathrm{OC}_{2} \mathrm{H}_{5}\right)_{4}$

$\mathrm{Si}\left(\mathrm{OC}_{2} \mathrm{H}_{5}\right)_{4} \rightarrow \mathrm{SiO}_{2}+4 \mathrm{C}_{2} \mathrm{H}_{5} \mathrm{OH} ; \mathrm{SiH}_{4} \rightarrow \mathrm{Si}+2 \mathrm{H}_{2}$

Amorphous silicon can be produced by reduction of silicon tetrahalogen or silicon dioxide with active metal or carbon, respectively. Furthermore, polycrystalline silicon can be obtained by annealing and heat processing of amorphous silicon, besides the modified Siemens Method.

As an important Si precursor, butyl-capped Si solutions are prepared by reduction of $\mathrm{SiCl}_{4}$ with sodium naphthalene at $400^{\circ} \mathrm{C}$ for $9 \mathrm{~h}$ (mix with butyl-lithium in stirring overnight subsequently, remove the solvent and naphthalene by rotary evaporator under vacuum at $120^{\circ} \mathrm{C}$ respectively, and partition $\mathrm{NaCl}$ from $\mathrm{LiCl}$ using excess $\mathrm{n}$-hexane and water). The final product, a pale-yellow viscous gel is given in the end [16-20]. The reaction process is as follows.

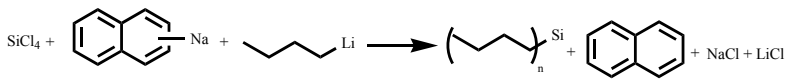

\subsection{Preparation Techniques for Various Nanostructure Silicon Anode Materials}

Various methods [16-19,21-32,39] including sacrificing template method, sol-gel method, template etching, chemical vapor deposition, sputtering, etc, are listed in Table 2. Pore structure of mesoporous materials, macroporous materials, nanoporous materials, as well as fibers, nanowires, nanotubes and other structures can be obtained by the methods mentioned above.

Templates methods including hard or soft templates are important methods for preparation of various Silicon nanostructure materials. Silicon porous nano-materials, e.g., hollow $0 \mathrm{D}$ nanoparticle or porous $3 \mathrm{D}$ nanoparticle, can be obtained by Si precursor with silica nanoparticle as template [17]. Silicon nanowire or Silicon nanotube can be prepared by $\mathrm{Si}$ precursor with SBA-15 or $\mathrm{Al}_{2} \mathrm{O}_{3}$ membrane template, respectively $[16-19,39]$. Moreover, B-dope monocrystalline silicon can be allowed to produce mesoporous silicon nanowires by etching of appropriate concentration of mixture of $\mathrm{AgNO}_{3}$ and $\mathrm{HF}$ for $3-4 \mathrm{~h}$ at $25-50^{\circ} \mathrm{C}$ [26]. In addition, solvothermal preparation method can provide silicon nanocrystals or nanotubes throught the action of $\mathrm{SiO}$ [33].

Silicon film can be obtained by chemical vapor deposition, thermal evaporation, magnetron sputtering, which can produce the film of $\mathrm{Si}, \mathrm{Al}, \mathrm{Sn}$, etc. [32]. The magnetron sputtering [21-23] of co-deposition can provide composite of two kinds of materials, such as Si-Al. Ballmilling [29-31] is also an important method for provide composite materials, such as $\mathrm{Si}-\mathrm{C}, \mathrm{Si}_{\mathrm{x}} \mathrm{Co}_{0.3} \mathrm{Cu}_{0.3} \mathrm{Cr}_{0.6} \mathrm{Al}_{0.2}$ modified graphite sphere composties, etc., through blending and doping various elements in the Silicon materials.

Table 2. Preparation Methods of Si Composite Materials and their Capacities

\begin{tabular}{|c|c|c|}
\hline Methods Strategies & Structures and Component Characteristic & Capacity \\
\hline combinatorial sputtering & $\begin{array}{c}\text { Si-Al-Sn films [21] } \\
\text { Si-Al thin film }[22,23]\end{array}$ & $\begin{array}{c}1500 \sim 50 \text { cycles } \\
2258 \sim 10,1500 \sim 350(0.5 \mathrm{C})\end{array}$ \\
\hline Catalytic etching (HF- $\mathrm{AgNO}_{3}$, etc.) & $\begin{array}{c}\text { Silicon nanowire array films [24] } \\
\text { silicon nanowire p-n junction diode arrays [25] } \\
\text { Single Crystalline Mesoporous Silicon Nanowires [26] } \\
\text { photoluminescent silicon nanoparticles [27] } \\
\text { silicon nanowire of controlled diameter, length, density [28] }\end{array}$ & $1000 \sim 30$ cycles \\
\hline ball milling & $\begin{array}{c}\text { Ti-Si and Ti-Si-Al alloy [29] } \\
\text { Si/carbon coating [30] } \\
\mathrm{Si}_{\mathrm{x}} \mathrm{Co}_{0.3} \mathrm{Cu}_{0.3} \mathrm{Cr}_{0.6} \mathrm{Al}_{0.2} / \text { modified graphite sphere [31] }\end{array}$ & $\begin{array}{l}500 \sim 40 \text { cycles } \\
620 \sim 100 \text { cycles } \\
1700 \sim 40 \text { cycles }\end{array}$ \\
\hline Pulse electrodeposition & Sn film [32] & $679 \sim$ \\
\hline Templates methods & $\begin{array}{c}\text { Nanoscale Si coating on pore-walls of } \mathrm{SnO}_{2} \text { nanotube [16] } \\
\text { Three-Dimensional Porous Silicon Particles [17] } \\
\text { Silicon Nanotube [18] } \\
\mathrm{Sn}_{0.9} \mathrm{Si}_{0.1} / \mathrm{Carbon} \text { Core-Shell Nanoparticles [19] } \\
\text { Mesoporous Si@Carbon Core-Shell Nanowires [39] }\end{array}$ & $\begin{array}{l}1800 \rightarrow 1600 \sim 90 \text { cycles } \\
2800 \sim 100 \text { cycles } \\
3247 \sim 200 \text { cycles } \\
964 \sim(0.3 \mathrm{C}) \\
3163 \sim 80 \text { cycles }\end{array}$ \\
\hline
\end{tabular}




\section{THE PROSPECTS OF HIGH CAPACITY Si COMPOSITE ANODE MATERIALS}

\subsection{The Characteristics of High Capacity Si Composite Anode Materials}

As shown in Tables $\mathbf{3}$ and $\mathbf{4}$, there are many kinds of siliconfree and silicon-containing composite materials, with various structures, components, and preparation methods, as anodes candidates of Li-ion secondary batteries. For example, mesoporous nanowires of silicon/carbon, mesoporous titanium dioxide-coated silicon, mesoporous polyaniline-titanium dioxide composite, macroporous nickel-tin, mesoporous silicatitania, silicon nanowires, carbon-silicon core-shell nanowires, carbon fiber/silica composite, tin oxide nanofibers tubesilicon/tin, silicon/single-walled carbon nanotube.
However, the anode materials with high capacity of over $1000 \mathrm{mAh} / \mathrm{g}$, good cycle performance of over 100 times, are listed as followed:

(1) Amorphous silicon or silicon/aluminum film of micron-size prepared by magnetron sputtering of codeposition can provide about $2000 \mathrm{mAh} / \mathrm{g}$ of specific capacities [22, 34].

(2) Amorphous silicon nanowires prepared by CVD of silane can possess $2000 \mathrm{mAh} / \mathrm{g}$ of specific capacities during 2000 cycles [43].

(3) Butyl-capped Si nanotubes as well as the mesoporous $\mathrm{Si} /$ carbon core-shell nanowires/nanofiber prepared by template methods can supply $2000-3247 \mathrm{mAh} / \mathrm{g}$ of specific capacities during 80-200 cycles [18, 39, 46].

Table 3. The Capacity Properties of Si-Free Anode Materials

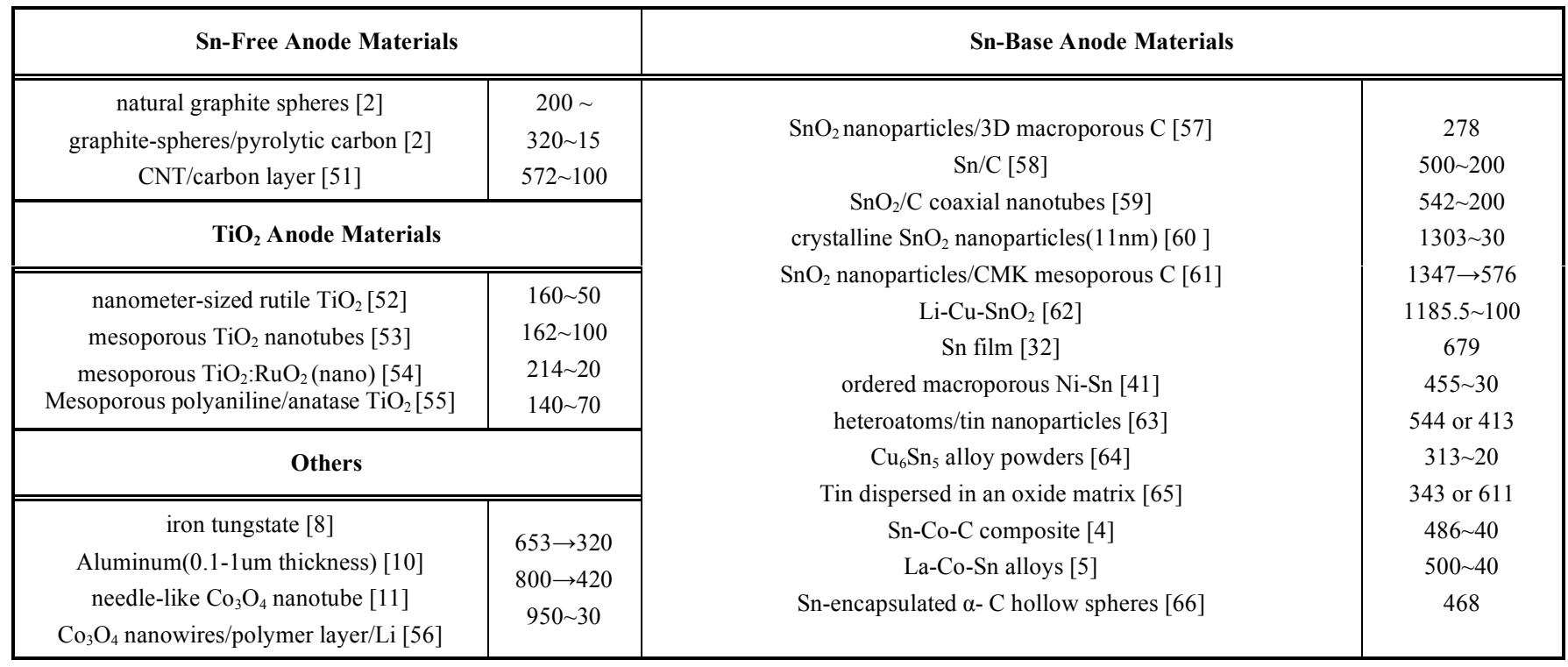

Table 4. The Capacity Properties of Si-Containing Anode Materials

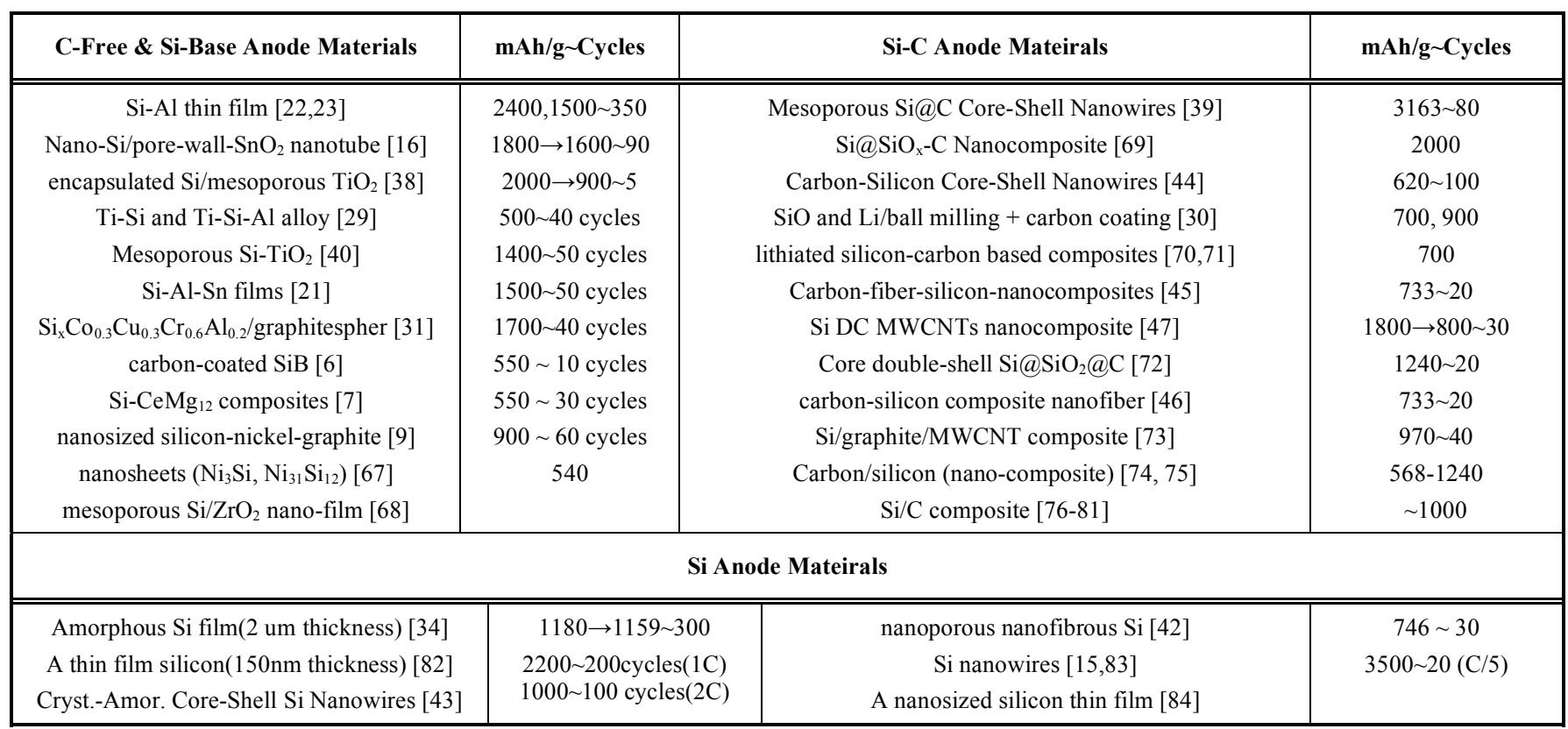


From the high capacity anode materials mentioned above, the highest capacity anode materials are Si nanotubes prepared by template methods, while their too high cost to be applied to commercial process. Amorphous silicon nanowires also have high capacity while their low tap densities remain a problem. As for the amorphous silicon/aluminum film, thickened Si/Al film anode materials have been prepared by magnetron sputtering, which has $2000 \mathrm{mAh} / \mathrm{g}$ of average capacity at rate of $1.1 \mathrm{~mA} / \mathrm{mg}$ over 140 cycles.

\subsection{The Prospects for Silicon Composite Anode Materials of Li-Ion Secondary Batteries}

Sub-micron material for anode materials will be paid attention to, because both nanostructure materials and micron materials are problematic: the former has high activity but instability, while the latter has high stability but low activity. Therefore, sub-micron material might balance between the active and stability.

Series of preparation skills could be adopted. Gradient buffer material [85] can be help to minimize the destruction of the buffer layer around silicon, because it is not easy for one layer materials to sufficiently buffer the huge volume variation caused instantly by silicon sites. Also, amorphous silicon composite materials with multi-layer films should be considered for their anisotropic properties. In addition, UV/X-ray curing methods and imprinting technology [86] can give excellent adhesive power and tailor-made microstructures, which could be considered for its more efficient.

With the further mechanics research of Li-ion secondary batteries [87-93] and the lithium-sulphur batteries [94, 95], the Si-containing anode materials with higher performances will be well-designed and developed in low-cost way.

\section{REFERENCES}

[1] Tarascon JM, Armand M. Issues and challenges facing rechargeable lithium batteries. Nature 2001; 414: 359-67.

[2] Zhang HL, Liu SH, Li F, et al. Electrochemical performance of pyrolytic carbon-coated natural graphite spheres. Carbon 2006; 44: 2212-8.

[3] Valvo M, Lafont U, Munao D, et al. Electrospraying-assisted synthesis of tin nanoparticles for Li-ion battery electrodes. J Power Sources 2009; 189: 297-302.

[4] Chen ZX, Qian JF, Ai XP. Preparation and electrochemical performance of Sn-Co-C composite as anode material for Li-ion batteries. J Power Sources 2009; 189: 730-2.

[5] Wang G, Lu ZW, Gao XP, et al. Electrochemical performance of La-Co-Sn alloys as anode materials for Li-ion batteries. J Power Sources 2009; 189: 655-9.

[6] Kim HS, Chung KY, Cho BW. Electrochemical properties of carbon-coated $\mathrm{Si} / \mathrm{B}$ composite anode for lithium ion batteries. J Power Sources 2009; 189: 108-13.

[7] Lu ZW, Wang G, Gao XP, et al. Electrochemical performance of $\mathrm{Si}-\mathrm{CeMg}_{12}$ composites as anode materials for Li-ion batteries. J Power Sources 2009; 189: 832-6.

[8] Kendrick E, Swiatek A, Barker J. Synthesis and characterisation of iron tungstate a node materials, J Power Sources 2009; 189: 611-5.

[9] Wang XY, Wen ZY, Liu Y, et al. Preparation and characterization of a new nanosized silicon-nickel-graphite composite as anode material for lithium ion batteries. J Power Sources 2009; 189: 1216.

[10] Hamon Y, Brousse T, Jousse F. Aluminum negative electrode in lithium ion batteries. J Power Sources 2001; 97-98: 185-7.

[11] Lou XW, Deng D, Lee JY, et al. Self-supported formatnion of needlelike $\mathrm{Co}_{3} \mathrm{O}_{4}$ nanotubes and their application as lithium-ion battery electrodes. Adv Mater 2008; 20: 258.
[12] Liu C, Li F, Ma LP, et al. Advanced materials for energy storage. Adv Mater 2010; 22: E1-E35.

[13] Cho J. Porous Si anode materials for lithium rechargeable batteries J Mater Chem 2010; 20: 4009-14.

[14] Beaulieu LY, Eberman KW, Turner RL, et al. Colossal reversible volume variations in lithium alloys. Electrochem Solid-State Lett 2001; 4: A137-A140.

[15] Chan CK, Peng HL, Liu G, et al. High-performance lithium battery anodes using silicon nanowires. Nat Nanotechnol 2008; 3: 31-5.

[16] Lee WJ, Park MH, Wang Y, et al. Nanoscale Si coating on the pore walls of $\mathrm{SnO}_{2}$ nanotube anode for $\mathrm{Li}$ rechargeable batteries. Chem Commun 2010; 46: 622-4

[17] Kim H, Han B, Choo J, et al. Three-dimensional porous silicon particles for use in high-performance lithium secondary batteries. Angew Chem Int Ed 2008; 47: 10151-4.

[18] Park M-H, Kim MG, Joo J, et al. Silicon nanotube battery anodes. Nano Lett 2009; 9: 3844-7.

[19] Kwon YJ, Kim H, Doo S-G, et al. $\mathrm{Sn}_{0.9} \mathrm{Si}_{0.1} /$ Carbon Core-shell nanoparticles for high-density lithium storage materials. Chem Mater 2007; 19: 982-6.

[20] Lee H, Cho J. Sn ${ }_{78} \mathrm{Ge}_{22} @$ Carbon Core-Shell Nanowires as Fast and High-Capacity Lithium Storage Media. Nano Lett 2007; 7: 263841.

[21] Hatchard TD, Topple JM. Fleischauer MD, et al. Electrochemical performance of SiAlSn films prepared by combinatorial sputtering. Electrochem Solid State Lett 2003; 6: A129-A132.

[22] Chen LB, Xie JY, Yu HC. Si-Al thin film anode material with superior cycle performance and rate capability for lithium ion batteries. Electrochimica Acta 2008; 53: 8149-53.

[23] Fleischauer MD, Obrovac MN, Dahn JR. Al-Si Thin-Film negative electrodes for Li-ion batteries. J Electrochem Soc 2008; 155: A851A854.

[24] Huang R, Zhu J. Silicon nanowire array films as advanced anode materials for lithium-ion batteries. Mat Chem Phys 2010; 121: 51922.

[25] Peng KQ, Huang ZP, Zhu J. Fabrication of large-area silicon nanowire p-n junction diode arrays. Adv Mater 2004; 16: 73-6.

[26] Hochbaum AI, Gargas D, Hwang YJ, et al. Single crystalline Mesoporous Silicon Nanowires. Nano Lett 2009; 9: 3550-4.

[27] $\mathrm{Li} \mathrm{XG}, \mathrm{He} \mathrm{YQ}$, Talukdar SS, et al. Process for preparing macroscopic quantities of brightly photoluminescent silicon nanoparticles with emission spanning the visible spectrum. Langmuir 2003; 19: 8490-6.

[28] Huang ZP, Fang H, Zhu J. Fabrication of silicon nanowire arrays with controlled diameter, length, and density. Adv Mater 2007; 19: 744-8.

[29] Lee KM, Lee YS, Kim YW, et al. Electrochemical characterization of $\mathrm{Ti}-\mathrm{Si}$ and $\mathrm{Ti}-\mathrm{Si}-\mathrm{Al}$ alloy anodes for $\mathrm{Li}$-ion batteries produced by mechanical ball milling. J Alloys Compd 2009; 472: 461-5.

[30] Liu Y, Wen ZY, Wang XY, et al. Improvement of cycling stability of $\mathrm{Si}$ anode by mechanochemcial reduction and carbon coating. J Power Sources 2009; 189: 480-4.

[31] Li MQ, Yu ZL, Qu MZ. Preparation of $\mathrm{Si}_{x} \mathrm{Co}_{0.3} \mathrm{Cu}_{0.3} \mathrm{Cr}_{0.6} \mathrm{Al}_{0.2} /$ modified graphite sphere composites and their electrochemical performance as anode materials for Li-ion batteries. J Alloys Compd 2010; 491: 643-8.

[32] Ui K, Kikuchi S, Kadoma Y, et al. Electrochemical characteristics of Sn film prepared by pulse electrodeposition method as negative electrode for lithium secondary batteries. J Power Sources 2009; 189: 224-9.

[33] Qiu J, Shen WQ, Yu RJ, et al., Solvothermal preparation of silicon nanocrystals. Chem Lett 2008; 37: 644-5.

[34] Yang HB, Fu PP, Zhang HF. Amorphous Si film anode coupled with $\mathrm{LiCoO}_{2}$ cathode in Li-ion cell. J Power Sources 2007; 174, 533-7.

[35] Hatchard TD, Dahn JR. In situ XRD and electrochemical study of the reaction of lithium with amorphous silicon. J Electrochem Soc 2004; 151: A838-A842.

[36] Kwon Y, Park GS, Cho JH. Synthesis and electrochemical properties of lithium-electroactive surface-stabilized silicon quantum dots. Electrochim Acta 2007; 52: 4663-8.

[37] Kwon Y, Cho J. High capacity carbon-coated Si70Sn30 nanoalloys for lithium battery anode material. Chem Commun 2008; 9: 110911

[38] Park SE, Kim BE, Lee SW, et al. Employment of encapsulated Si with mesoporous $\mathrm{TiO}_{2}$ layer as anode material for lithium 
secondary batteries. Trans Nonferrous Met Soc China 2009; 19: 1023-6.

[39] Kim H, Cho J. Superior lithium electroactive mesoporous Si@carbon core-shell nanowires for lithium battery anode material. Nano Lett 2008; 8: 3688-91.

[40] Zeng ZY, Tu JP, Huang XH, et al. Electrochemical properties of a mesoporous $\mathrm{Si}_{-} \mathrm{TiO}_{2}$ nanocomposite film anode for lithium-ion batteries. J Electrochem Soc 2008; 11: A105-A107.

[41] Nishikawa K, Dokko K, Kinoshita K, et al. Three-dimensionally ordered macroporous $\mathrm{Ni}-\mathrm{Sn}$ anode for lithium batteries. J Power Sources 2009; 189: 726-9.

[42] Lv RG, Yang J, Gao PF, et al. Electrochemical behavior of nanoporous/nanofibrous $\mathrm{Si}$ anode materials prepared by mechanochemical reduction. J Alloys Compd 2010; 490: 84-7.

[43] Cui LF, Ruffo R, Chan CK, et al. Crystalline-amorphous core-shell silicon nanowires for high capacity and high current battery electrodes. Nano Lett 2009; 9: 491-5.

[44] Cui LF, Yang Y, Hsu CM, et al. Carbon-silicon core-shell nanowires as high capacity electrode for lithium ion batteries. Nano Lett 2009; 9: 3370-4.

[45] Wolf $\mathrm{H}$, Pajkic $\mathrm{Z}$, Gerdes $\mathrm{T}$, et al. Carbon-fiber-siliconnanocomposites for lithium-ion battery anodes by microwave plasma chemical vapor deposition. J Power Sources 2009; 190: 157-61.

[46] Wang L, Ding CX, Zhang LC. A novel carbon-silicon composite nanofiber prepared via electrospinning as anode material for high energy-density lithium ion batteries. J Power Sources 2010; 195: 5052-6.

[47] Zhou ZB, Xu YH, Liu WG. High capacity Si/DC/MWCNTs nanocomposite anode materials for lithium ion batteries. J Alloys Compd 2010; 493: 636-9.

[48] Yin JT, Wada M, Yamamoto K, et al. Micrometer-scale amorphous Si thin-film electrodes fabricated by electron-beam deposition for Li-ion batteries. J Electrochem Soc 2006; 153: A472-A477.

[49] Fong R, von Sacken U, Dahn JR. Studies of lithium intercalation into carbons using nanaqueous electrochemical-cells. J Electrochem Soc 1990; 137: 2009-13.

[50] Chen LB, Wang K, Xie XH, et al. Effect of vinylene carbonate (VC) as electrolyte additive on electrochemical performance of $\mathrm{Si}$ film anode for lithium ion batteries. J Power Sources 2007; 174: 538-43.

[51] Chen J, Minett AI, Liu Y, et al. Direct growth of flexible carbon nanotube electrodes. Adv Mater 2008; 20: 566.

[52] Hu YS, Kienle L, Guo YG, et al. High lithium electroactivity of nanometer-sized rutile $\mathrm{TiO}_{2}$. Adv Mater 2006; 18: 1421-6.

[53] Wang KX, Wei MD, Morris MA, et al. Mesoporous titania nanotubes: Their preparation and application as electrode materials for rechargeable lithium batteries. Adv Mater 2007; 19: 3016-20.

[54] Guo YG, Hu YS, Sigle W, et al. Superior electrode performance of nanostructured mesoporous $\mathrm{TiO}_{2}$ (anatase) through efficient hierarchical mixed conducting networks. Adv Mater 2007; 19: 2087.

[55] Lai C, Li GR, Dou YY, Gao XP. Mesoporous polyaniline or polypyrrole/anatase $\mathrm{TiO}_{2}$ nanocomposite as anode materials for lithium-ion batteries. Electrochimica Acta 2010; 55: 4567-72.

[56] Nam KT, Kim DW, Yoo PJ, et al. Virus-enabled synthesis and assembly of nanowires for lithium ion battery electrodes. Science 2006; 312: 885-8.

[57] Lee KT, Lytle JC, Ergang NS, et al. Synthesis and rate performance of monolithic macroporous carbon electrodes for lithium-ion secondary batteries. Adv Funct Mater 2005; 15: 54756.

[58] Derrien G, Hassoun J, Panero S, et al. Nanostructured Sn-C composite as an advanced anode material in high-performance lithium-ion batteries. Adv Mater 2007; 19: 2336.

[59] Wang Y, Zeng HC, Lee JY. Highly reversible lithium storage in porous $\mathrm{SnO}_{2}$ nanotubes with coaxially grown carbon nanotube overlayers. Adv Mater 2006; 18: 645.

[60] Deng D, Lee JY. Hollow core-shell mesospheres of crystalline $\mathrm{SnO}_{2}$ nanoparticle aggregates for high capacity $\mathrm{Li}^{+}$ion storage. Chem Mater 2008; 20: 1841-6.

[61] Fan J, Wang T, Yu CZ, et al. Ordered, nanostructured tin-based oxides/carbon composite as the negative-electrode material for lithium-ion batteries. Adv Mater 2004; 16: 1432.

[62] Yu Y, Chen CH, Shi Y. A tin-based amorphous oxide composite with a porous, spherical, multideck-cage morphology as a highly reversible anode material for lithium-ion batteries. Adv Mater 2007; 19: 993-7.

[63] Alcántara R, Ortiz G, Rodríguez I, et al. Effects of heteroatoms and nanosize on tin-based electrodes. J Power Sources 2009; 189: 309 14.

[64] Ju SH, Jang HC, Kang YC. Electrochemical properties of $\mathrm{Cu}_{6} \mathrm{Sn}_{5}$ alloy powders directly prepared by spray pyrolysis. J Power Sources 2009; 189: 163-8.

[65] Mouyane M, Aldon L, Womes M, et al. Tin dispersed in an oxide matrix as negative electrode material for Li-ion batteries. J Power Sources 2009; 189: 818-22.

[66] Lee KT, Jung YS, Oh SM. Synthesis of tin-encapsulated spherical hollow carbon for anode material in lithium secondary batteries. J Am Chem Soc 2003; 125: 5652-3

[67] Zhang HL, Li F, Liu C, et al. The facile synthesis of nickel silicide nanobelts and nanosheets and their application in electrochemical energy storage. Nanotechnology 2008; 19: 165606.

[68] Shi DQ, Tu JP, Yuan YF. Preparation and electrochemical properties of mesoporous $\mathrm{Si} / \mathrm{ZrO}_{2}$ nanocomposite film as anode material for lithium ion battery. Electrochem Commun 2006; 8: $1610-4$.

[69] Hu YS, Demir-Cakan R, Titirici MM, et al. Superior storage performance of a $\mathrm{Si} @ \mathrm{SiO}_{\mathrm{x}} / \mathrm{C}$ nanocomposite as anode material for lithium-ion batteries. Angew Chem Int Ed Engl 2008; 47: 1645-9.

[70] Datta MK, Kumta PN. In situ electrochemical synthesis of lithiated silicon-carbon based composites anode materials for lithium ion batteries. J Power Sources 2009; 194: 1043-52.

[71] Seong IW, Kim KT, Yoon WY. Electrochemical behavior of a lithium-pre-doped carbon-coated silicon monoxide anode cell. J Power Sources 2009; 189: 511-4.

[72] Su LW, Zhou Z, Ren MM. Core double-shell Si@SiO $@ \mathrm{C}$ nanocomposites as anode materials for Li-ion batteries. Chem Commun 2010; 46: 2590-2.

[73] Zhang Y, Zhang XG, Zhang HL, et al. Composite anode material of silicon/graphite/carbon nanotubes for Li-ion batteries. Electrochim Acta 2006; 51: 4994-5000.

[74] Si Q, Hanai K, Imanishi N, et al. Highly reversible carbon-nanosilicon composite, anodes for lithium rechargeable batteries. J Power Sources 2009; 189: 761-5.

[75] Holzapfel M, Buqa H, Scheifele W, et al. A new type of nano-sized silicon/carbon composite electrode for reversible lithium insertion. Chem Commun 2005; 12: 1566-8

[76] Luo ZJ, Fan DD, Liu XL, et al. High performance silicon carbon composite anode materials for lithium ion batteries. J Power Sources 2009; 189: 16-21.

[77] Jo YN, Kim Y, Kim JS, et al. Si-graphite composites as anode materials for lithium secondary batteries. J Power Sources 2010; 195: 6031-6.

[78] Eker Y, Kierzek K, Raymundo-Pinero E, et al. Effect of electrochemical conditions on the performance worsening of $\mathrm{Si} / \mathrm{C}$ composite anodes for lithium batteries. Electrochimica Acta 2010; 55: 729-36.

[79] Liu Y, Wen ZY, Wang XY, et al. Electrochemical behaviors of $\mathrm{Si} / \mathrm{C}$ composite synthesized from F-containing precursors. J Power Sources 2009; 189: 733-7.

[80] Wen ZS, Yang J, Wang BF, et al. High capacity silicon/carbon composite anode materials for lithium ion batteries. Electrochem Commun 2003; 5: 165-8.

[81] Saint J, Morcrette M, Larcher D, et al. Towards a fundamental understanding of the improved electrochemical performance of silicon-carbon composites. Adv Funct Mater 2007; 17: 1765-74.

[82] S. Ohara, Suzuki J, Sekine K. A thin film silicon anode for Li-ion batteries having a very large specific capacity and long cycle life. J Power Sources 2004; 136: 303-6.

[83] Chan CK, Peng HL, Liu G, et al. High-performance lithium battery anodes using silicon nanowires. Nat Nanotechnol 2008; 3: 31-5.

[84] Guo H, Zhao HL, Yin CL, et al. A nanosized silicon thin film as high capacity anode material for Li-ion rechargeable batteries. Mater Sci Eng B 2006; 131: 173-6.

[85] Sun YK, Myung ST, Park BC, et al. High-energy cathode material for long-life and safe lithium batteries. Nat Mater 2009; 8: 320-4.

[86] Decker C. Kinetic study and new applications of UV radiation curing. Macromol Rapid Commun 2002; 23: 1067-93.

[87] Kang B, Ceder G. Battery materials for ultrafast charging and discharging. Nature 2009; 458: 190-3. 
[88] Gibot P, Casas-Cabanas M, Laffont L, et al. Room-temperature single-phase $\mathrm{Li}$ insertion/extraction in nanoscale $\mathrm{Li}_{x} \mathrm{FePO}_{4}$. Nat Mater 2008; 7: 741-7.

[89] Chan CK, Ruffob R, Hong SS, et al. Structural and electrochemical study of the reaction of lithium with silicon nanowires. J Power Sources 2009; 189: 34-9.

[90] Gadjourova Z, Andreev YG, Tunstall DP. Ionic conductivity in crystalline polymer electrolytes. Nature 2001; 412: 520-3.

[91] Foll H, Christophersen M, Carstensen J, et al. Formation and application of porous silicon. Mater Sci Eng R 2002; 39: 93-141.
[92] Lou XW, Archer LA, Yang ZC. Hollow micro-/nanostructures: synthesis and applications. Adv Mater 2008; 20: 3987-4019.

[93] Song T, Xia JL, Lee J-H, et al. Arrays Of Sealed Silicon Nanotubes As Anodes For Lithium Ion Batteries. Nano Lett 2010; 10: 1710-6.

[94] Ji XL, Lee KT, Nazar LF. A highly ordered nanostructured carbonsulphur cathode for lithium-sulphur batteries. Nat Mater 2009; 8: 500-6.

[95] Choi JW, Kima JK, Cheruvally G. Rechargeable lithium/sulfur battery with suitable mixed liquid electrolytes. Electrochimica Acta 2007; 52: 2075-82.

(C) Wang et al.; Licensee Bentham Open.

This is an open access article licensed under the terms of the Creative Commons Attribution Non-Commercial License (http://creativecommons.org/licenses/by-nc/3.0/) which permits unrestricted, non-commercial use, distribution and reproduction in any medium, provided the work is properly cited. 